\title{
Caracterização físico-química das águas superficiais do Rio São Francisco nos municípios de Juazeiro/BA e Petrolina/PE
}

A crescente expansão demográfica e industrial observada nas últimas décadas trouxe como consequência o comprometimento das águas dos rios, lagos e reservatórios. Além dos problemas relacionados à quantidade da água, a contaminação dos mananciais, principalmente, por atividades antrópicas, impede, por exemplo, seu uso direto para abastecimento humano e agrava o problema da escassez deste recurso. Isto é mais preocupante nas regiões áridas e semiáridas onde a água se tornou um fator limitante para o desenvolvimento urbano, industrial e agrícola. 0 principal aspecto considerado em relação à disponibilidade de água neste trabalho é a qualidade da água de abastecimento para uso humano, o que indica a importância da conservação das nascentes dos rios, fontes naturais da água na superfície terrestre. Dentro deste contexto se ressalta a importância de realizar um diagnóstico do estado dessas águas, a partir de análises físicoquímicas, com o objetivo de desenvolver um aporte de conhecimentos que serão úteis para identificar o impacto dos lançamentos oriundos da atividade humana sobre o rio São Francisco na região de estudo. Verificou-se que a atividade antrópica contribui para alterar a qualidade do rio, em especial com relação ao aumento do teor de fósforo total na água do rio. Apesar disso, a caracterização físico-química da água revelou concordância em grande parte com a Legislação, no caso de corpos d'água de classe 2.

Palavras-chave: Água; Semiárido; Caracterização Físico-Química; Qualidade; Sustentabilidade.

\section{Physical-chemical characterization of surface waters of São Francisco River at Juazeiro/BA and Petrolina/PE cities}

\begin{abstract}
The demographic growing and industrial expansion observed in recent decades has resulted in the deterioration of river, lake and reservoir waters. In addition to the problems related to the quantity of water, the contamination of water sources, mainly by anthropic activities, prevents, for example, their use for human supply and aggravates the problem of scarcity of this resource. This is more worrisome in arid and semi-arid regions, where water has become a limiting factor for urban, industrial and agricultural development. The main aspect considered in relation to the availability of water in this work is the quality of the water supply for human use, which indicates the importance of the conservation of river sources, natural sources of water on the land surface. Within this context, it is important to carry out a diagnosis of these waters, the polluting sources and their impacts on the environment, with the objective of developing a knowledge that will be useful in the analysis of the urban and rural sources conservation state of the river in the region of study. It was verified that antropogenic activity implies quality river alteration, specially increase in total fosforous concentration. Besides, the physicochemical analysis carried out showed great Legislation concordance, in case of class 2 water bodies.
\end{abstract}

Keywords: Water; Semiarid; Physicochemical analysis; Quality; Sustainability.

Topic: Engenharia Ambiental

Reviewed anonymously in the process of blind peer.

Carlos Laécio Evangelista França (ic)

Universidade Federal do Vale do São Francisco, Brasil

http://lattes.cnpq.br/0716371192165728

http://orcid.org/0000-0003-1659-1776 evangelista_franca@hotmail.com

Fernanda Santos Carvalho dos Anjos (D) Universidade Federal do Vale do São Francisco, Brasil

http://lattes.cnpq.br/8974662290514159 http://orcid.org/0000-0003-4095-5488

fernanda.anjos@univasf.edu.br

Débora Santos Carvalho dos Anjos (iD) Instituto Federal do Sertão Pernambucano, Brasil http://lattes.cnpq.br/6183551107865718 http://orcid.org/0000-0001-8647-2612 debora.santos@ifsertao-pe.edu.br

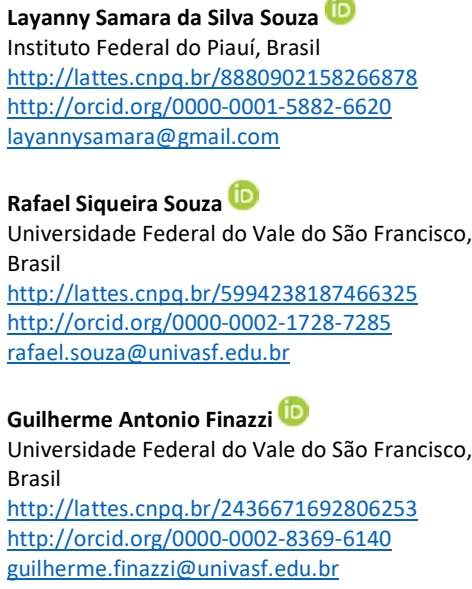

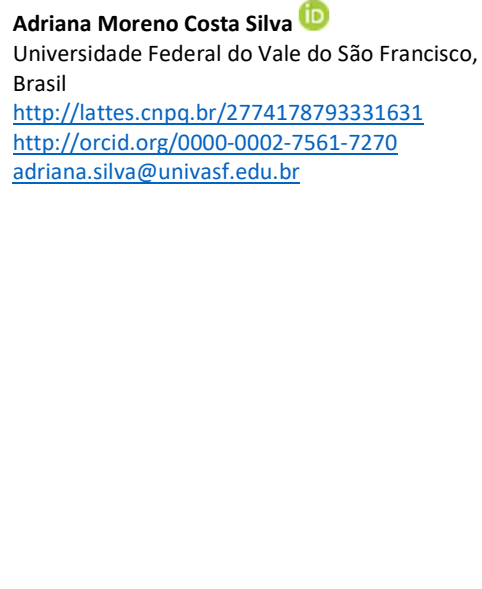

Referencing this:

FRANÇA, C. L. E.; ANJOS, F. S. C.; ANJOS, D. S. C.; SOUZA, L. S. S.; SOUZA, R. S.; FINAZZI, G. A.; SILVA, A. M. C.. Caracterização físicoquímica das águas superficiais do Rio São Francisco nos municípios de Juazeiro/BA e Petrolina/PE. Revista Ibero Americana de Ciências Ambientais, v.10, n.6, p.218-230, 2019. DOI: http://doi.org/10.6008/CBPC2179-6858.2019.006.0019 


\section{INTRODUÇÃO}

A água é fundamental para a vida. Durante muito tempo, foi considerada um recurso infinito. Entretanto, apesar de existir em abundância, nem toda água é diretamente aproveitada pelo homem. Hoje, sabe-se que, em torno, de $97 \%$ da água disponível no Planeta Terra é salgada e está em oceanos e mares, enquanto que, aproximadamente, $3 \%$ é doce, mas se encontra em geleiras ou regiões subterrâneas (aquíferos), de difícil acesso (BAIRD, 2011). Seus múltiplos usos são indispensáveis a um largo espectro das atividades humanas, onde se destacam, entre outros, o abastecimento doméstico e público; os usos agrícola e industrial; produção de energia elétrica e as atividades de lazer e recreação.

A crescente expansão demográfica e industrial, aliada ao desenvolvimento socioeconômico ocorridos nas últimas décadas tem ocasionado impactos diversos nos recursos naturais, principalmente nos recursos hídricos. Em nível global, devido aos processos de uso e de poluição crescentes, provenientes de fontes pontuais, como os resíduos domésticos ou industriais, e não-pontuais, como a agricultura, os recursos hídricos tendem a se tornar mais escassos, caso não haja ações enérgicas visando à melhoria da gestão da oferta e da demanda da água (INS, 2012).

A falta de recursos financeiros nos países em desenvolvimento tem agravado esse problema, devido ao empecilho à aplicação de medidas corretivas para evitar a situação de escassez, associado a razões de dificuldades técnicas inerentes a essas ações, à falta de aplicação de procedimentos que gerem ferramentas de apoio à gestão e sua conveniente divulgação aos interessados. A gestão adequada da água deve ser objeto de um plano que contemple os múltiplos usos desse recurso, desenvolvendo e aperfeiçoando as técnicas de utilização, tratamento e recuperação de nossos mananciais.

Dentre os maiores desafios da gestão de recursos hídricos está a redução das cargas poluidoras nos corpos d'água. A poluição hídrica pode ter origem química, física ou biológica, sendo que em geral a adição de um tipo destes poluentes altera também as outras características da água. Desta forma, o conhecimento destas interações é de extrema importância para que se possa lidar da melhor forma possível com as fontes de poluição (PEREIRA, 2013).

Os ecossistemas aquáticos podem ser considerados como os receptores de poluentes mais importantes provenientes de: esgotos domésticos (poluentes orgânicos biodegradáveis, nutrientes e bactérias), os quais representam uma das principais fontes poluidoras; esgotos industriais (poluentes orgânicos e inorgânicos, dependendo da atividade industrial), onde apenas uma pequena quantidade recebe algum tipo de tratamento e o restante é lançado nos corpos d'água 'in natura'; cargas difusas urbana e agrícola (poluentes advindos da drenagem destas áreas: fertilizantes, defensivos agrícolas, fezes de animais e material em suspensão). A carga poluidora dos despejos, e a capacidade dos rios em assimilar os agentes tóxicos, são as variáveis que determinam o impacto num córrego, rio ou qualquer outro sistema receptor (GONÇALVES, 2007).

A Agência Nacional de Águas - ANA (2013b), em seu levantamento que gerou o estudo da Conjuntura dos recursos hídricos no Brasil, defende que é urgente o monitoramento da qualidade das águas das bacias 
para controlar e evitar contaminações futuras, tanto das fontes hídricas quanto dos solos. É necessário sensibilizar os órgãos gestores para um programa de despoluição e revitalização.

A região semiárida brasileira apresenta peculiaridades que torna ainda mais específico o tratamento de água de abastecimento, pois se trata de uma região com características naturais complexas e altamente heterogêneas em relação à chuva, ao solo e a vegetação. A ocorrência de baixas taxas de precipitação e elevadas taxas evapotranspirométricas favorecem a concentração de solutos nas águas, e outros fatores naturais, principalmente a geologia, têm forte influência na qualidade das águas. As relações entre homem e ambiente delineiam os aspectos sociais, econômicos e políticos dessa sociedade tão marcada pela escassez de água. Por isso, a água tornou-se um fator limitante para o desenvolvimento urbano, industrial e agrícola do semiárido (CBHSF, 2004).

O Rio São Francisco, também conhecido como o Rio da Integração Nacional, tornou-se uma das principais vias de penetração para o interior. É o maior rio totalmente brasileiro com mais de $2700 \mathrm{Km}$. Suas águas banham cinco estados brasileiros (Minas Gerais, Bahia, Pernambuco, Alagoas e Sergipe). É o principal gerador de energia elétrica para o Nordeste. Por isso é considerado de grande importância natural, cultural e socioeconômica para o Brasil.

Apesar dos municípios de Juazeiro/BA e Petrolina/PE estarem às margens do Rio São Francisco, a população enfrenta comumente graves problemas de escassez de água, o que coloca em risco a sua própria sobrevivência, agravando as questões de saúde, além de provocar enormes dificuldades econômicas. Isso ocorre por dois motivos principais: o primeiro deles refere-se à diluição de despejos de origem humana, industrial e agrícola que degrada a qualidade das águas (ANA, 2012); o outro está associado a determinados usos dos recursos hídricos que fazem com que parte da água que é utilizada não retorne ao corpo d'água (BARRETO, 2015). De acordo com BRAGA et al. (2005), tais usos são denominados consuntivos. Por exemplo, a irrigação, na qual parte da água fornecida é retirada para constituição da vegetação ou sofre evapotranspiração; o abastecimento urbano, no qual existe uma perda de água significativa durante o sistema de distribuição; e o abastecimento industrial, no qual também ocorrem perdas no sistema de distribuição ou então incorporação da água ao produto manufaturado.

No Brasil, o problema de viabilidade econômica do investimento público torna-se ainda mais agudo, em razão da elevada parcela da população de baixa renda. No entanto, vale ressaltar que a água de qualidade também é um fator de exclusão social, uma vez que a população de baixa renda dificilmente tem condições de pagar assistência médica para remediar as doenças de veiculação hídrica, decorrentes da ausência de saneamento básico ou até mesmo comprar água de qualidade para beber.

Para realizar o controle da poluição das águas de nossos rios e reservatórios, utilizam-se os padrões de qualidade da água, que definem os limites de concentração a que cada substância presente na água deve obedecer. Esses padrões dependem da classificação das águas, que é estabelecida segundo seus usos preponderantes, por legislação específica (Resolução CONAMA N. 357/2005) (BRASIL, 2005), a qual estabeleceu a classificação das águas doces, salobras e salinas do Território Nacional, fixou diretrizes e parâmetros visando o enquadramento dos corpos d'água e definiu o enquadramento como o 
estabelecimento do nível de qualidade (classe) a ser alcançado e/ou mantido em um segmento de corpo d'água ao longo do tempo. A mencionada Resolução adota nove diferentes classes para as águas, estabelecendo para cada uma delas limites e/ou condições de qualidade a serem respeitados, de modo a assegurar seus usos preponderantes, sendo que os limites são mais restritivos quanto mais nobre for o uso pretendido.

A Lei 9.433, de 08 de janeiro de 1997 (BRASIL, 1997), referendada no documento elaborado pela ANA (2007), que faz um panorama do enquadramento dos corpos d'água do Brasil, determinou que este fosse um dos instrumentos de gestão da Política Nacional de Recursos Hídricos e definiu seus objetivos como assegurar às águas qualidade compatível com os usos mais exigentes a que forem destinadas e diminuir os custos de combate à poluição das águas, mediante ações preventivas permanentes (ANA, 2013a).

O referido instrumento é fundamental, em especial, nas bacias hidrográficas onde existem conflitos de uso. Sua aplicação acarreta consequências econômicas, sociais e ambientais, propiciando aos diferentes gestores de água uma ferramenta para assegurar a disponibilidade quantitativa e qualitativa da água em uma bacia hidrográfica, além de fortalecer a relação entre a gestão dos recursos hídricos e a gestão ambiental, promovendo a proteção e a recuperação dos recursos hídricos. No caso do Rio São Francisco, em particular, esta ação se torna mais importante, pois o uso da água envolve agricultura, transposição, navegação, demandas energéticas e ecológicas (CBHSF, 2004).

Atualmente, alguns parâmetros físicos, químicos e microbiológicos comuns, ao qual se somam outros parâmetros específicos, servem para avaliar a qualidade da água, mas seus índices variam de acordo com o uso e ocupação do solo na região de influência direta do ponto de amostragem; são eles: oxigênio dissolvido - o excesso de dejetos orgânicos e tóxicos na água reduz o nível de oxigênio e impossibilita o ciclo biológico normal; demanda bioquímica de oxigênio (DBO); demanda química de oxigênio (DQO); amônia; cloretos; condutividade elétrica 'in loco'; coliformes fecais; temperatura; $\mathrm{pH}$; nitrato; nitrito; nitrogênio orgânico; fósforo total; sólidos dissolvidos; sólidos em suspensão; sólidos totais e turbidez (ANA, 2012). Porém, por significar condições apenas momentâneas, a análise das condições físico-químicas nem sempre indica a qualidade real da água. Seria necessária a interação de diferentes áreas da ciência que atuam sobre a realidade ambiental para se realizar uma análise mais aprofundada, e assim, verdadeiramente adequada, do manancial em questão.

Portanto, para o avanço das pesquisas ambientais há necessidade de se implementar um sistema de monitoramento na região para a realização de análises da água, o qual fortalecerá não só a rede de pesquisa, mas também nas atividades acadêmicas e de extensão, a fim de fornecer subsídios científicos, para os órgãos responsáveis, no intuito de melhorar a qualidade ambiental das comunidades do semiárido próximas para o Desenvolvimento Regional Sustentável. É importante salientar que a qualidade das águas muda ao longo do ano, em função de fatores meteorológicos; eventual sazonalidade de lançamentos poluidores e das vazões, sendo necessário um trabalho de monitoramento contínuo em suas águas.

'Sustentabilidade' é um termo utilizado pela primeira vez em 1982, no sentido da diminuição do uso de recursos naturais (OVERBY, 1982). A preocupação com o uso indiscriminado da energia e das matérias- 
primas na indústria, para a fabricação de produtos mais duráveis e recicláveis iniciou-se no âmbito da economia, e disseminou o termo que atualmente é muito utilizado com relação à preservação do meio ambiente. E, neste contexto, a preservação de águas fluviais é muito importante, tanto com relação à flora e à fauna, quanto ao abastecimento humano. Por isso, muito se fez e se faz no sentido de verificar a qualidade das águas. Com relação ao tema, podem-se citar os trabalhos realizados por Rizzutto et al. (2006), Silva et al. (2018a; 2018b), Oliveira et al. (2018), Silva et al. (2017), Krika et al. (2016) e Zhang et al. (2016).

A importância do Rio São Francisco no Nordeste Brasileiro foi tema de estudos internacionais. Jennerjahn et al. (1999) analisaram a quantidade de aminoácidos, hexosaminas e carboidratos nos sedimentos e no material em suspensão na foz do rio, e identificaram que a composição é similar à de outras regiões marinhas. Observaram que a perda do teor de carbono destas partículas é maior do que a perda na água, por conta de decomposição severa na interface sedimento-água, provavelmente devido à alta concentração de oxigênio em grande profundidade, à baixa taxa de sedimentação e ao padrão de distribuição de tirosina em sedimento coletado a $1280 \mathrm{~m}$ de profundidade. Os autores sugerem que a tirosina é um indicador das condições redox da matéria orgânica da região.

Costa et al. (2017) realizaram análises físico-químicas de águas dos rios da bacia hidrográfica do Rio São Francisco no estado de Minas Gerais. As autoras identificaram que alguns parâmetros medidos em áreas urbanizadas e industrializadas excederam os patamares exigidos por legislação: manganês, fósforo, turbidez, cor, número de coliformes fecais e arsênio. A causa indicada para estes excessos é a poluição por despejos domésticos; os processos naturais erosivos e causas antropogênicas; como contaminação por atividades mineradoras. Levando em consideração a poluição já detectada no rio São Francisco, é importante fazer um monitoramento constante da qualidade de suas águas.

\section{METODOLOGIA}

A área abrangida por este estudo compreende a bacia hidrográfica do rio São Francisco entre os municípios de Juazeiro/BA e Petrolina/PE, conforme pode ser observado na Figura 1.

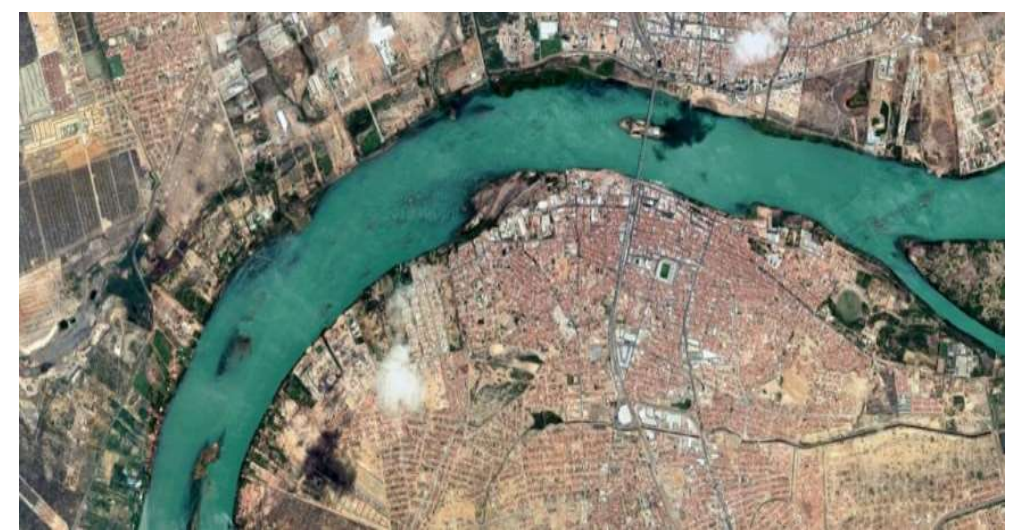

Figura 1: Área do Rio São Francisco entre os municípios de Petrolina/PE e Juazeiro/BA.

Foram realizadas coletas de água do rio São Francisco ao longo da área compreendida entre os municípios de Petrolina e Juazeiro, em locais onde se observam as disposições de resíduos líquidos provenientes dos municípios em questão. Os principais parâmetros avaliados nas análises de água foram: 
Temperatura da água e do ar; Cor; Turbidez; pH; Condutividade elétrica; Sólidos totais dissolvidos (STD); Alcalinidade total em $\mathrm{CaCO}_{3}$; Cloreto; Oxigênio dissolvido (OD), Potencial de Redução-Oxidação (ORP); Alcalinidade, Dureza, Resistividade, Fosfato, Nitrogênio total Kjeldahl, Nitrito, Nitrato e $\mathrm{DBO}_{5}$.

As principais metodologias de análise que foram realizadas estão descritas na ABNT, na última edição do manual da FUNASA e na última edição do livro Standard Methods for Water and Wastewater (APHA, 2012), consagrada mundialmente como a principal referência em métodos e procedimentos analíticos de parâmetros de qualidade da água e esgoto. As análises de Temperatura, pH, Condutividade elétrica, Sólidos totais dissolvidos, Oxigênio dissolvido, Potencial de Redução-Oxidação e resistividade dos meses de 05/2017 e 04/2018 foram realizadas com equipamento multiparâmetros HANNA modelo HI 9828.

\section{RESULTADOS}

As Tabelas 1, 2, 3, 4 e 5 apresentam os resultados obtidos das análises físico-químicas das amostras de água do Rio São Francisco, nos meses de 11/2011, 05/2013, 09/2013, 05/2017 e 04/2018, respectivamente, tendo como valores de referência os descritos na Resolução CONAMA 357 (BRASIL, 2005), para verificar se essas águas encontram-se de acordo com os parâmetros de qualidade de água exigidos conforme esta resolução. A tabela 6 apresenta os resultados de temperatura, pH, oxigênio dissolvido, nitrito, nitrato, fósforo total e $\mathrm{DBO}_{5}$ das coletas realizadas nos mesmos pontos dos meses indicados nas tabelas anteriores.

Tabela 1: Resultados analíticos das amostras de água coletas no Rio São Francisco, no mês de 11/2011.

\begin{tabular}{|c|c|c|c|c|c|c|c|c|c|}
\hline Amostras & $\begin{array}{l}\text { Temperatura } \\
\left({ }^{\circ} \mathrm{C}\right)\end{array}$ & pH & $\begin{array}{l}\text { Oxig. } \\
\text { Dissolvido } \\
\text { (mg/L) }\end{array}$ & $\begin{array}{l}\text { Cloretos } \\
\text { (mg/L) }\end{array}$ & $\begin{array}{l}\text { Dureza } \\
\text { Total } \\
\text { (mg/L) }\end{array}$ & $\begin{array}{l}\text { Alcalinidade } \\
\text { (mg/L) }\end{array}$ & $\begin{array}{l}\text { Orto- } \\
\text { fosfato } \\
\text { (mg/L) }\end{array}$ & $\begin{array}{l}\text { Fosfato } \\
\text { total } \\
(\mathrm{mg} / \mathrm{L})\end{array}$ & $\begin{array}{l}\text { Nitrito } \\
\text { (mg/L) }\end{array}$ \\
\hline VMP(1) & Indiferente & $\begin{array}{|ll|}6,0 & a \\
8,5 & \\
\end{array}$ & $>5$ & $<250$ & $<500$ & 10 a 350 & $<0,1$ & $<0,1$ & $<1,0$ \\
\hline 1.1 & 26,5 & 5,5 & 8,30 & 0,236345 & 72,0 & 81,6 & 0,189 & 0,49 & 4,724 \\
\hline 2.1 & 26,5 & 5,5 & 8,00 & 0,088625 & 68,0 & 87,0 & 0,160 & 0,26 & 5,414 \\
\hline 3.1 & 26,5 & 5,5 & 8,20 & 0,354500 & 70,0 & 95,2 & 0,110 & 0,27 & 6,103 \\
\hline 4.1 & 26,5 & 5,5 & 6,40 & 0,101281 & 70,0 & 81,6 & 0,201 & 0,40 & 9,207 \\
\hline 5.1 & 26,5 & 5,5 & 6,80 & 0,088625 & 136,0 & 88,9 & 0,162 & 0,29 & 6,448 \\
\hline 6.1 & 26,5 & 6,0 & 6,40 & 0,236345 & 62,0 & 97,6 & 0,191 & 0,24 & 6,793 \\
\hline 7.1 & 26,5 & 6,0 & 7,40 & 0,161120 & 54,0 & 97,6 & 0,164 & 0,23 & 6,448 \\
\hline 8.1 & 26,5 & 5,0 & 8,00 & 0,050658 & 58,0 & 83,3 & 0,176 & 0,26 & 33,690 \\
\hline 9.1 & 26,5 & 5,0 & 6,90 & 0,078770 & 76,0 & 97,6 & 0,216 & 0,43 & 57,138 \\
\hline 10.1 & 26,5 & 4,5 & 7,40 & 0,062179 & 54,0 & 95,2 & 0,133 & 0,26 & 13,000 \\
\hline 11.1 & 26,5 & 6,5 & 6,16 & 0,078770 & 70,0 & 95,2 & 0,145 & 0,37 & 23,345 \\
\hline
\end{tabular}

NOTAS: (1) Valor Máximo Permitido para águas doces de classe 2 - Segundo resolução $n^{\circ} 357$ CONAMA (BRASIL, 2005).

Tabela 2: Resultados analíticos das amostras de água coletadas no Rio São Francisco, no mês 05/2013.

\begin{tabular}{|l|l|l|l|l|l|}
\hline Amostras & Temperatura $\left({ }^{\circ} \mathbf{C}\right)$ & $\mathbf{p H}$ & Oxigênio Dissolvido $(\mathbf{m g} / \mathbf{L})$ & Condutividade Elétrica $(\mathbf{m S} / \mathbf{c m})$ & $\mathbf{D B O}_{\mathbf{5}}(\mathbf{m g} / \mathbf{L})$ \\
\hline VMP(1) & Indiferente & $\mathbf{6 , 0}$ a $\mathbf{9 , 0}$ & $\mathbf{> 5}$ & $\mathbf{5}$ & $<\mathbf{5}$ \\
\hline $\mathbf{1 . 3}$ & 26,0 & 8,8 & 8,12 & 52,04 & 7,040 \\
\hline $\mathbf{2 . 3}$ & 25,0 & 8,6 & 8,68 & 49,08 & 8,320 \\
\hline $\mathbf{3 . 3}$ & 25,0 & 7,1 & 7,15 & 280,40 & $\mathrm{NR}$ \\
\hline $\mathbf{4 . 3}$ & 25,0 & 8,3 & 9,31 & 59,04 & 8,000 \\
\hline $\mathbf{5 . 3}$ & 25,0 & 8,1 & 8,96 & 49,66 & 7,680 \\
\hline $\mathbf{6 . 3}$ & 26,0 & 7,6 & 8,33 & 58,42 & 6,464 \\
\hline $\mathbf{7 . 3}$ & 26,0 & 7,7 & 8,12 & 56,82 & 7,488 \\
\hline $\mathbf{8 . 3}$ & 25,0 & 7,8 & 6,67 & 56,95 & 4,992 \\
\hline
\end{tabular}

NOTAS: (1) Valor Máximo Permitido para águas doces de classe 2 - Segundo resolução n 357 CONAMA (BRASIL, 2005). 
Tabela 3: Resultados analíticos das amostras de água coletadas no Rio São Francisco, no mês 09/2013.

\begin{tabular}{|c|c|c|c|c|c|c|}
\hline Amostras & $\begin{array}{l}\text { Temperatura } \\
\left({ }^{\circ} \mathrm{C}\right)\end{array}$ & $\mathrm{pH}$ & $\begin{array}{l}\text { Oxigênio } \\
\text { Dissolvido } \\
\text { (mg/L) }\end{array}$ & $\begin{array}{l}\text { Condutividade } \\
\text { Elétrica } \\
(\mathrm{mS} / \mathrm{cm})\end{array}$ & Turbidez (NTU) & $\begin{array}{l}\text { Sólidos Totais } \\
\text { Dissolvidos } \\
\text { (mg/L) }\end{array}$ \\
\hline VMP(1) & Indiferente & 6,0 a 9,0 & $>5$ & $<0,5$ & $<100$ & $<500$ \\
\hline 1.3 & 23,0 & 7,5 & 7,46 & 0,04 & 3,4 & 0,028 \\
\hline 2.3 & 22,9 & 7,4 & 7,53 & 0,06 & 3,6 & 0,041 \\
\hline 3.3 & 25,1 & 7,2 & 6,59 & 0,25 & 67,8 & 0,154 \\
\hline 4.3 & 25,2 & 7,2 & 7,93 & 0,03 & 5,2 & 0,018 \\
\hline 5.3 & 24,5 & 7,6 & 8,25 & 0,05 & 3,3 & 0,030 \\
\hline 6.3 & 23,0 & 7,4 & 7,67 & 0,06 & 3,8 & 7,673 \\
\hline 7.3 & 23,1 & 7,4 & 8,61 & 0,03 & 3,2 & 0,023 \\
\hline 8.3 & 22,5 & 6,8 & 7,77 & 0,06 & 3,1 & 0,039 \\
\hline
\end{tabular}

NOTAS: (1) Valor Máximo Permitido para águas doces de classe 2 - Segundo resolução $n^{\circ} 357$ CONAMA (BRASIL, 2005).

Tabela 4: Resultados analíticos das amostras de água coletadas no Rio São Francisco, no mês 05/2017.

\begin{tabular}{|c|c|c|c|c|c|c|c|c|c|c|c|c|}
\hline Amostras & $\begin{array}{l}\text { Temperatura } \\
\left({ }^{\circ} \mathrm{C}\right)\end{array}$ & $\mathrm{pH}$ & $\begin{array}{l}\text { Oxigênio } \\
\text { Dissolvido } \\
\text { (mg/L) }\end{array}$ & $\begin{array}{l}\text { Cloretos } \\
\text { (mg/L) }\end{array}$ & $\begin{array}{l}\text { Dureza } \\
\text { Total } \\
\text { (mg/L) }\end{array}$ & $\begin{array}{l}\text { Alcali- } \\
\text { nidade } \\
\text { ( } \mathrm{mg} / \mathrm{L})\end{array}$ & $\begin{array}{l}\text { Conduti- } \\
\text { vidade } \\
\text { Elétrica } \\
(\mathrm{mS} / \mathrm{cm})\end{array}$ & $\begin{array}{l}\text { Turbidez } \\
\text { (NTU) }\end{array}$ & $\begin{array}{l}\text { Sólidos } \\
\text { Totais } \\
\text { Dissolvidos } \\
\text { (mg/L) }\end{array}$ & $\begin{array}{l}\text { Potencial } \\
\text { de } \\
\text { Redução- } \\
\text { Oxidação } \\
\text { (ORP) }\end{array}$ & 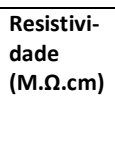 & $\begin{array}{l}\text { Cor } \\
\text { Aparente } \\
\text { (uC) }\end{array}$ \\
\hline VMP(1) & Indiferente & $\begin{array}{l}6,0 \\
\text { a } \\
9,0\end{array}$ & $>5$ & $<250$ & $<500$ & $\begin{array}{ll}10 & a \\
350 & \end{array}$ & $<0,5$ & $<100$ & $<500$ & $<500$ & ND & $<75$ \\
\hline 1.7 & 26,7 & 8,2 & 5,46 & 0,008997 & 104,4 & 16,0 & 0,07 & 20,0 & 35,0 & 72,4 & 0.0143 & 50,3 \\
\hline 2.7 & 26,9 & 8,0 & 4,36 & 0,008497 & 100,8 & 16,0 & 0,07 & 19,8 & 35,0 & 73,6 & 0,0144 & 50,8 \\
\hline 3.7 & 26,5 & 8,0 & 4,59 & 0,007998 & 100,4 & 8,0 & 0,07 & 19,2 & 35,0 & 71,4 & 0,0143 & 48,8 \\
\hline 4.7 & 26,9 & 7,7 & 4,16 & 0,007998 & 100,8 & 6,0 & 0,07 & 19,2 & 35,0 & 74,7 & 0,0144 & 49,9 \\
\hline 5.7 & 26,5 & 8,0 & 5,05 & 0,008497 & 97,2 & 16,0 & 0,07 & 20,0 & 35,0 & 62,6 & 0,0144 & 50,7 \\
\hline 6.7 & 26,8 & 7,7 & 4,91 & 0,008997 & 104,4 & 18,0 & 0,08 & 17,6 & 36,0 & 72,0 & 0,0137 & 46,2 \\
\hline 7.7 & 26,5 & 7,6 & 5,20 & 0,007998 & 97,2 & 20,0 & 0,07 & 18,0 & 36,0 & 70,2 & 0,0138 & 47,5 \\
\hline 8.7 & 26,0 & 8,0 & 5,70 & 0,007998 & 108,0 & 18,0 & 0,07 & 18,3 & 35,0 & 61,4 & 0,0145 & 47,1 \\
\hline 9.7 & 26,1 & 8,4 & 6,54 & 0,008497 & 108,0 & 16,0 & 0,07 & 17,1 & 36,0 & 55,5 & 0,0139 & 44,5 \\
\hline 10.7 & 27,0 & 7,8 & 5,07 & 0,008497 & 111,6 & 18,0 & 0,07 & 19,5 & 35,0 & 73,0 & 0,0143 & 51,2 \\
\hline 11.7 & 26,5 & 8,8 & 5,87 & 0,007998 & 104,4 & 16,0 & 0,09 & 15,6 & 45,0 & 97 & 0,01111 & 40,3 \\
\hline
\end{tabular}

NOTAS: (1) Valor Máximo Permitido para águas doces de classe 2 - Segundo resolução n 357 CONAMA (BRASIL, 2005).

Tabela 5: Resultados analíticos das amostras de água coletadas no Rio São Francisco, no mês 04/2018.

\begin{tabular}{|c|c|c|c|c|c|c|c|c|c|}
\hline Amostras & $\begin{array}{l}\text { Temperatura } \\
\left({ }^{\circ} \mathrm{C}\right)\end{array}$ & $\mathrm{pH}$ & $\begin{array}{l}\text { Condutividade } \\
\text { Elétrica } \\
(\mathrm{mS} / \mathrm{cm})\end{array}$ & $\begin{array}{l}\text { Turbidez } \\
\text { (NTU) }\end{array}$ & $\begin{array}{l}\text { Oxigênio } \\
\text { Dissolvido } \\
\text { (mg/L) }\end{array}$ & $\begin{array}{l}\text { Sólidos } \\
\text { Totais } \\
\text { Dissolvidos } \\
\text { (mg/L) }\end{array}$ & $\begin{array}{l}\text { Fósforo } \\
\text { Total } \\
\text { (mg/L) }\end{array}$ & $\begin{array}{l}\text { Nitrito } \\
\text { (mg/L) }\end{array}$ & $\begin{array}{l}\text { Nitrato } \\
\text { (mg/L) }\end{array}$ \\
\hline VMP(1) & Indiferente & $\begin{array}{ll}6,0 & a \\
9,0 & \end{array}$ & $<0,5$ & $<100$ & $>5$ & $<500$ & $<0,1$ & $<1,0$ & $<10,0$ \\
\hline 1.8 & 26,0 & 8,2 & 0,09 & 1,51 & 7,55 & 32,1 & 6,46 & 0,048 & 0,028 \\
\hline 2.8 & 26,0 & 8,3 & 0,07 & 1,62 & 7,04 & 36,0 & 11,71 & 0,164 & 0,004 \\
\hline 3.8 & 26,0 & 7,6 & 0,07 & 1,72 & 5,63 & 31,4 & 16,07 & 0,053 & 0,003 \\
\hline 4.8 & 26,0 & 8,5 & 0,07 & 1,43 & 5,89 & 33,7 & 5,32 & 0,093 & 0,002 \\
\hline 5.8 & 26,0 & 7,2 & 0,07 & 1,43 & 5,38 & 34,8 & 5,71 & 0,048 & 0,003 \\
\hline 6.8 & 26,0 & 7,6 & 0,07 & 2,33 & 6,49 & 32,5 & 11,12 & 0,05 & 0,002 \\
\hline 7.8 & 26,0 & 7,8 & 0,07 & 1,67 & 6,34 & 32,3 & 2,94 & 0,05 & 0,001 \\
\hline 8.8 & 26,0 & 7,2 & 0,07 & 1,53 & 6,69 & 32,9 & 0,81 & 0,055 & 0,003 \\
\hline 9.8 & 26,0 & 8,4 & 0,07 & 1,69 & 7,26 & 33,0 & 6,31 & 0,058 & 0,002 \\
\hline 10.8 & 26,0 & 8,3 & 0,07 & 1,39 & 8,35 & 32,6 & 9,03 & 0,046 & 0,001 \\
\hline 11.8 & 26,0 & 8,3 & 0,07 & 1,42 & 6,58 & 32,0 & 8,10 & 0,051 & 0,003 \\
\hline
\end{tabular}

NOTAS: (1) Valor Máximo Permitido para águas doces de classe 2 - Segundo resolução n 357 CONAMA (BRASIL, 2005).

Tabela 6: Resultados analíticos das amostras de água coletas no Rio São Francisco, entre 11/2011 e 04/2018.

\begin{tabular}{|l|l|l|l|l|l|l|l|l|}
\hline Amostras & Mês de coleta & $\begin{array}{l}\text { Temperatura } \\
\left({ }^{\circ} \mathbf{C}\right)\end{array}$ & $\mathbf{p H}$ & $\begin{array}{l}\text { Oxigênio } \\
\text { Dissolvido } \\
(\mathbf{m g} / \mathbf{L})\end{array}$ & $\begin{array}{l}\text { Fosfato } \\
\text { total } \\
(\mathbf{m g} / \mathbf{L})\end{array}$ & $\begin{array}{l}\text { Nitrito } \\
(\mathbf{m g} / \mathbf{L})\end{array}$ & $\begin{array}{l}\mathbf{D B O}_{\mathbf{5}} \\
(\mathbf{m g} / \mathbf{L})\end{array}$ & $\begin{array}{l}\text { Nitrato } \\
(\mathbf{m g} / \mathbf{L})\end{array}$ \\
\hline VMP(1) & & Indiferente & $\mathbf{6 , 0}$ a 8,5 & $>\mathbf{5}$ & $<\mathbf{0 , 1}$ & $<\mathbf{1 , 0}$ & $<\mathbf{5}$ & $<\mathbf{1 0 , 0}$ \\
\hline I & $\mathbf{1 1 / 2 0 1 1}$ & 26,5 & 5,5 & 8,30 & 0,49 & 4,724 & - & - \\
& $\mathbf{0 5 / 2 0 1 3}$ & 26,0 & 8,8 & 8,12 & - & - & 7,040 & - \\
& $\mathbf{0 9 / 2 0 1 3}$ & 23,0 & 7,5 & 7,46 & - & - & - & - \\
& $\mathbf{0 5 / 2 0 1 7}$ & 26,5 & 8,0 & 4,59 & - & - & - & - \\
& $\mathbf{0 4 / 2 0 1 8}$ & 26,0 & 8,4 & 5,70 & 6,31 & 0,117 & - & 0,006 \\
\hline II & $\mathbf{1 1 / 2 0 1 1 0 5 / 2 0 1 3}$ & 26,5 & 5,5 & 8,00 & 0,26 & 5,414 & - & - \\
\hline
\end{tabular}




\begin{tabular}{|l|l|l|l|l|l|l|l|l|}
\hline & $\mathbf{0 9 / 2 0 1 3}$ & 25,0 & 8,6 & 8,68 & - & - & 8,320 & - \\
& $\mathbf{0 5 / 2 0 1 7}$ & 23,0 & 7,4 & 7,53 & - & - & - & - \\
& $\mathbf{0 4 / 2 0 1 8}$ & 26,9 & 8,0 & 4,36 & - & - & - & - \\
& & 26,0 & 7,2 & 5,20 & 0,81 & 0,109 & - & 0,010 \\
\hline III & $\mathbf{1 1 / 2 0 1 1 0 5 / 2 0 1 3}$ & 26,5 & 5,5 & 6,80 & 0,37 & 6,448 & - & - \\
& $\mathbf{0 9 / 2 0 1 3}$ & 25,0 & 8,3 & 9,31 & - & - & 8,000 & - \\
& $\mathbf{0 5 / 2 0 1 7}$ & 25,2 & 7,2 & 7,93 & - & - & - & - \\
& $\mathbf{0 4 / 2 0 1 8}$ & 26,1 & 8,4 & 6,54 & - & - & - & - \\
& & 26,0 & 8,2 & 7,55 & 6,46 & 0,092 & - & 0,08 \\
\hline IV & $\mathbf{1 1 / 2 0 1 1 0 5 / 2 0 1 3}$ & 26,5 & 5,0 & 8,00 & 0,26 & 33,690 & - & - \\
& $\mathbf{0 9 / 2 0 1 3}$ & 26,0 & 7,6 & 8,33 & - & - & 6,464 & - \\
& $\mathbf{0 5 / 2 0 1 7}$ & 23,0 & 7,4 & 7,67 & - & - & - & - \\
& $\mathbf{0 4 / 2 0 1 8}$ & 26,8 & 7,7 & 4,91 & - & - & - & - \\
& & 26,0 & 8,5 & 5,89 & 5,32 & 0,208 & - & 0,007 \\
\hline V & $\mathbf{1 1 / 2 0 1 1 0 5 / 2 0 1 3}$ & 26,5 & 6,5 & 6,16 & 0,37 & 23,345 & - & - \\
& $\mathbf{0 9 / 2 0 1 3}$ & 25,0 & 7,8 & 6,67 & - & - & 4,992 & - \\
& $\mathbf{0 5 / 2 0 1 7}$ & 22,5 & 6,8 & 7,77 & - & - & - & - \\
& $\mathbf{0 4 / 2 0 1 8}$ & 26,5 & 7,6 & 5,20 & - & - & - & - \\
& & 26,0 & 7,6 & 5,63 & 16,07 & 0,103 & - & 0,011 \\
\hline
\end{tabular}

NOTAS: (1) Valor Máximo Permitido para águas doces de classe 2 - Segundo resolução n 357 CONAMA (BRASIL, 2005).

\section{DISCUSSÃO}

A partir do banco de dados obtido com a análise das amostras de água do Rio São Francisco, podese perceber que a temperatura da água oscilou entre $25,0^{\circ} \mathrm{C}$ e $27,0^{\circ} \mathrm{C}$, ou seja, não sofreu grandes variações durante o período da pesquisa, com exceção das coletas do mês de $09 / 2013$, cuja variação foi entre $22,5^{\circ} \mathrm{C}$ e $25,2^{\circ} \mathrm{C}$. Também, neste mês, pode-se observar que a temperatura da água foi menor, provavelmente devido ao resfriamento do ar na época do inverno, anterior à coleta. Apesar da resolução no 357 CONAMA (BRASIL, 2005) não definir limite de temperatura para o consumo humano, é importante, para a fauna e flora local, não sofrer com variações abruptas de temperatura. Mas é importante salientar que, no mês 04/2018, a temperatura do ar no instante da coleta (horário próximo às $9 \mathrm{~h} 30$ ) foi medida e resultou $24,0^{\circ} \mathrm{C}$ em todos os pontos, indicando que a água do rio foi aquecida por algum fenômeno produzido pelo homem como, por exemplo, o despejo de efluentes domésticos, mesmo que tratados.

Com referência ao $\mathrm{pH}$, pode-se notar que a maioria dos dados entre 05/2013 e 04/2018 se encontraram dentro dos padrões estipulados pela Resolução CONAMA 357 (BRASIL, 2005), para corpos hídricos de classe 2, ou seja, pH entre 6 e 9. Com relação ao mês 11/2011, pode-se verificar que apenas três amostras se enquadram na resolução CONAMA, sendo os outros pontos de coleta inadequados para práticas como pesca, agricultura ou consumo. Este fato se deve provavelmente a uma maior quantidade de despejos lançados ao longo do curso do rio que, por depender da degradação fermentativa proporcionada pela atividade microbiana, leva à formação de ácidos que se dissolvem na água. Em outras palavras, os baixos valores de $\mathrm{pH}$ se devem à falta de tratamento de esgoto adequado na época. Após 11/2011, o pH da água do rio aumenta por causa da diminuição da quantidade de despejos não-tratados no rio, provavelmente devido à melhoria da eficiência das Estações de Tratamento de Esgoto (ETEs) instaladas na cidade de Petrolina.

Quanto ao oxigênio dissolvido (OD), é um dos parâmetros mais importantes para exame da qualidade da água, pois revela a possibilidade de manutenção de vida dos organismos aeróbios. Durante a estabilização da matéria orgânica, as bactérias fazem uso do oxigênio nos seus processos respiratórios, podendo vir a causar uma redução da sua concentração no meio. Dependendo da magnitude desse fenômeno, podem vir 
a morrer diversos seres aquáticos, inclusive os peixes. Observando o disposto nas Tabelas 1 a 5, pode-se notar que a maioria dos valores de OD são maiores que os limites estabelecidos pelo CONAMA. Isso se deve ao fato de que as amostras terem sido coletadas superficialmente, onde há uma grande quantidade de oxigênio dissolvido pela atmosfera. Também, pode-se perceber que apenas quatro amostras de 05/2017 (Tabela 4) apresentam valores menores que $5,00 \mathrm{mg} / \mathrm{L}$, contrariando os valores permitidos pela legislação vigente. Verificou-se que, nos pontos de coleta destas amostras, o rio sofre grande impacto dos efluentes lançados, oriundos da atividade humana, evidenciados pela presença de vegetação baronesa. Desta forma, há necessidade urgente de intervenção no tratamento destes efluentes, de modo que o impacto ambiental de sua disposição no manancial diminua a níveis aceitáveis.

Pode-se perceber na Tabela 6 que, ao longo dos anos, a concentração deste gás diminui na água, atingindo um estado crítico em 05/2017. Com a diminuição da vazão do rio, não somente a turbidez aumenta, atrapalhando a fotossíntese, como também a profundidade do rio torna-se menor, propiciando o escape de OD para a atmosfera. Já em 04/2018 a concentração volta a aumentar, provavelmente devido à diminuição da turbidez do rio. Este fato se deve à construção de barreiras para contenção da lama tóxica extravasada das barragens rompidas em MG, que também impede o carreamento de sólidos para a região, fenômeno que ocorria naturalmente em anos anteriores. Ainda assim, a concentração de OD está próxima ao limite estabelecido por legislação, e por isso pode-se concluir que a vida dos organismos aeróbios do rio está em risco, necessitando ações urgentes para evitar maiores degradações.

O conhecimento do teor de cloretos das águas tem por finalidade obter informações sobre o seu grau de mineralização ou indícios de poluição, como esgotos domésticos e resíduos industriais das águas. Os cloretos, mesmo em razoáveis concentrações, não são nocivos aos seres humanos, a não ser o cloreto de sódio, que causa hipertensão e, em termos ambientais, os cloretos estão relacionados com o potencial osmótico, que afeta a vida dos seres aquáticos de água doce, mas ainda assim, em nenhuma das coletas, a concentração de cloretos ultrapassou o valor de $250 \mathrm{mg} / \mathrm{L}$ permitido pela resolução.

Geralmente, quanto mais dura for a água, menos tóxica ela é para a vida aquática. De acordo com os dados das Tabelas 1 e 4, conclui-se que, utilizando a classificação de dureza de Durfor et al. (1964), as águas do rio São Francisco em 11/2011 são classificadas como moles, exceto em um único ponto, no qual a água pode ser considerada dura. Em 05/2017 as águas são classificadas como moderadamente duras. Em todos os casos, obedecem ao máximo permitido por legislação.

A alcalinidade é a medida total das substâncias presentes na água, e capazes de neutralizarem ácidos. A alcalinidade das águas naturais é fundamentalmente devida a hidróxidos, carbonatos e bicarbonatos. A alcalinidade presente na água auxilia na determinação da dosagem das substâncias floculantes, no tratamento da água e de despejos industriais. Junto com outros parâmetros analisados, fornece informações para o estudo das características corrosivas ou incrustantes da água. Do ponto de vista sanitário a alcalinidade não tem significado relevante, mesmo para valores elevados. No entanto as águas de alta alcalinidade são desagradáveis ao paladar e a associação com pH elevado, excesso de dureza e de sólidos dissolvidos, no conjunto, é que podem ser prejudiciais. Para proteção da vida aquática, a capacidade de 
tamponamento deve ser pelo menos igual a $20 \mathrm{mg} / \mathrm{L}$, o que é condizente com os valores observados em 11/2011 (Tabela 1). Sendo a alcalinidade muito baixa (abaixo de $20 \mathrm{mg} / \mathrm{L}$ ), pode haver quedas rápidas do $\mathrm{pH}$, devidas a chuvas e/ou descargas de efluentes ácidos e, esta condição foi determinada em quase todos pontos de amostragem de 05/2017 (Tabela 4), mostrando a influência dos despejos urbanos. Outro aspecto relacionado à alcalinidade é a facilidade de coagulação dentro do sistema de tratamento para abastecimento urbano (ETA). Quanto maior for a alcalinidade, maior é a dosagem de sulfato de alumínio necessária para realizar o tratamento da água por coagulação. O problema é que, caso os valores de alcalinidade e de turbidez sejam muito discrepantes, o tratamento necessita do uso de quantidade maior de produtos químicos, seja para regular a alcalinidade, seja para regular a turbidez.

Por ser menos abundante que o nitrogênio, o fósforo se constitui no principal fator limitante ao desenvolvimento de algas e plantas no meio aquático. Origina-se da dissolução de compostos do solo e da decomposição da matéria orgânica. $\mathrm{O}$ aporte de fósforo aos corpos d'água pode ocorrer por lançamentos de despejos domésticos e industriais, fertilizantes e lixiviação de criatório de animais. Em águas naturais não poluídas as concentrações desse parâmetro são comumente inferiores a $0,02 \mathrm{mg} / \mathrm{L}$. O papel do fósforo na eutrofização dos recursos hídricos é essencial, e a origem deste nutriente a partir de áreas agrícolas tem sido colocada em relevância como indicador de qualidade de água, já que outros indicadores como sólidos em suspensão e turbidez estão associados ao seu transporte. O principal meio aporte de fósforo à água é o uso urbano, seguido pelo uso agrícola (PEREIRA, 2013).

Os teores de fósforo total obtidos excederam o permitido pela legislação para águas de classe $2(0,1$ $\mathrm{mg} / \mathrm{L}$ para ambientes lóticos), sendo que os teores de orto-fosfato em 11/2011 já eram acima deste patamar. O fósforo total é um dos indicadores do Índice de Estado Trófico de um corpo hídrico, representando o enriquecimento de nutrientes na água que pode avançar para eutrofização. 0 processo de eutrofização da área que contempla as amostras é aparente pela presença das plantas Baronesas (Eichhornia crassipes). A elevação do teor de fósforo total pode ser causa pelo descarte de detergentes superfosfatados, matéria fecal ou drenagem de áreas agrícolas. Vale a pena frisar que, no que respeito à eutrofização o nitrogênio está interligado com o fósforo. Foi realizada análise de nitrogênio total, mas não houve resposta acima do limite de detecção do método; portanto, não se pode afirmar que há efetivamente o processo de eutrofização no rio.

A determinação do Nitrito em água é importante, pois ele indica o nível de poluição da água a partir de decomposição biológica de matéria orgânica nitrogenada de origem vegetal ou animal, de fertilizantes que foram carregados pelas chuvas, e também pela poluição de efluentes industriais. É importante salientar que pode provocar a produção de compostos cancerígenos e doenças infantis, quando em grande quantidade (PAJECKI, 2005). Os valores obtidos em 11/2011 estiveram acima dos limites estabelecidos pelo CONAMA, e em 04/2018 os valores estiveram bem abaixo. A justificativa para isso é que, em 2011, apenas parte do esgoto da cidade de Petrolina era tratado, visto que existiam apenas algumas ETEs em funcionamento. Já em Juazeiro não existia tratamento de esgoto. Deste modo, o esgoto bruto das cidades, naturalmente rico em nitritos, era despejado in natura no rio, por isso sua concentração alta. 
A condutividade elétrica depende da concentração dos íons presentes na solução e da temperatura e, por isso, essas medidas devem estar sempre associadas. Todos os pontos estão aptos para consumo humano em relação à condutividade.

A $\mathrm{DBO}_{5}$ ultrapassou o limite de 5,0mg/L estabelecido pela resolução 357 do CONAMA na maioria dos pontos de coleta em $05 / 2013$, indicando que a depreciação do nível de OD pode ser ainda maior do que a apresentada acima. A presença de algas nestas regiões na ocasião foi evidente, característica de excesso de nitrogênio e fósforo. $\mathrm{O}$ crescimento demasiado de plantas aquáticas provoca a diminuição do oxigênio dissolvido na água, impedimento da passagem de luz e consequentemente pode vir a levar morte dos peixes.

Em relação à turbidez, o limite máximo aceitável é de 100 UNT, observando-se que todos os pontos estão em conformidade com a resolução citada. É importante ressaltar que valores altos de turbidez podem estar relacionados à presença de matéria orgânica e/ou poderiam atrapalhar a atividade fotossintética de plantas aquáticas, reduzindo a concentração de OD, prejudicando, não só a flora, mas também a fauna local.

O teor de sólidos na água está diretamente relacionado com sua condutividade elétrica, uma vez que a condutividade depende da concentração de íons na solução e da temperatura. Quanto ao quesito, todas as amostras encontraram-se dentro dos padrões (máximo de $500 \mathrm{mg} / \mathrm{L}$ ).

O conhecimento dos valores de Potencial de Redução-Oxidação (ORP), de maneira geral, tem influência considerável na química e bioquímica da água, pois várias funções (como respiração) dependem dela. Em condição de alto teor de oxigênio dissolvido na água, os valores redox são altos, enquanto em caso de concentração baixa de $\mathrm{O}_{2}$, ou na sua ausência, processos redutivos são dominantes, como a respiração anaeróbica de bactérias. Contaminação (proteína de alimentos, excrementos) usualmente age de maneira redutiva, e água poluída sempre tem medidas de potencial redox bem inferiores à de água não poluída. No entanto, podemos observar que os valores encontrados estão dentro dos limites desejáveis.

A resistividade é a tendência oposta à condutividade, ou seja, indica o quanto a água resiste à passagem de corrente elétrica. É importante que não seja muito alta para evitar que a água apresente características corrosivas, mas também não pode ser muito baixa, para propiciar a troca iônica no corpo dos seres viventes do meio. Como o teor de sólidos de todas as amostras obedece ao disposto em legislação, pode-se afirmar que a resistividade elétrica da água está adequada, exceto apenas em 09/2013, quando encontrou-se teor de sólidos abaixo de $1,0 \mathrm{mg} / \mathrm{L}$.

A cor é um parâmetro indicativo de material orgânico proveniente da vegetação ribeirinha. Indica que há maior quantidade de material orgânico arrastado pelo rio. Apesar de não ser fator de poluição, a cor indica a degradação da vegetação marginal. Quanto maior a cor, maior é a degradação. Valores de cor muito altos indicam impacto ambiental. Pode-se notar na Tabela 4 que os valores de cor da água coletada obedecem à Legislação vigente.

A presença de nitrogênio é um indicativo da contaminação de água por atividades antrópicas (ALABURDA et al., 1998). Na forma de nitrato, não é tóxica, exceto quando houver bactérias redutoras de nitrato, que consomem nitrato para produzir nitrito, o qual é tóxico aos seres humanos, e em grandes concentrações pode causar doenças letais para as crianças, como a metahemoglobinemia infantil 
(FERNíCOLA et al., 1981). Tal preocupação quanto à presença em águas deriva dos efeitos tóxicos aos seres humanos. Teores de nitrato acima de $10 \mathrm{mg} / \mathrm{L}$ podem provocar a metahemoglobinemia infantil (doença do sangue azul) e a produção de nitrosaminas e nitrosamidas, ambas carcinogênicas (CABRAL, 2010). Considerando as amostras analisadas, os valores de nitrato estão de acordo com o exigido pela resolução ( $<10 \mathrm{mg} / \mathrm{L}$ ) em todos os pontos de amostragem. No entanto, considerando que em um dos pontos onde foi realizada a coleta desta amostra, a água é captada para tratamento para consumo humano, este resultado é preocupante. Soma-se a isso o fato que sua fonte de água está sujeita à contaminação por dejetos animais e humanos advindos das propriedades localizadas em porções adjacentes à montante do local da coleta, o que poderia explicar os valores encontrados de $\mathrm{DBO}_{5}$, nitrato, nitrito e fósforo total.

A análise da Tabela 6 revela que a qualidade da água do rio melhorou após 11/2011, com o efetivo funcionamento de ETEs em Petrolina; porém, ao longo do tempo, foi sendo degradada, devido à diminuição gradual da vazão do rio estabelecida pelo Estado e ao aumento das atividades antrópicas. Em 04/2018 alguns parâmetros apresentaram melhoria, o que pode ser explicado pela diminuição de carreamento de sólidos devido à construção de barreiras para contenção da lama tóxica extravasada das barragens rompidas em Minas Gerais/MG.

\section{CONCLUSÕES}

O estudo do banco de dados hidroquímicos mostra que em geral as águas coletadas na região de estudo traduzem uma baixa concentração dos principais parâmetros físico-químicos estudados. Porém, a alta concentração de fósforo total indica um teor de eutrofização da água que pode avançar. Foi possível obter, através deste estudo, observações contundentes sobre áreas que são passíveis de contaminação, apesar da análise preliminar evidenciar que as amostras de águas se encontram em conformidade, na maioria dos casos, com a Legislação, atendendo às normas da resolução.

Pôde-se constatar que em 11/2011 a qualidade da água do rio provavelmente era degradada por lançamento de esgoto bruto. Apesar de sua qualidade melhorar após 11/2011 com a implementação de ETEs, foi sendo degradada crescentemente ao longo dos anos, devido ao aumento da atividade humana e à diminuição da vazão do rio. Os dados de 04/2018 não refletem esta realidade, por não serem afetadas pelo carreamento natural de sólidos oriundos das águas à montante, reflexo da construção de barreiras para contenção da lama tóxica extravasada das barragens rompidas em Minas Gerais/MG. É necessária atenção especial para padrões que se distanciam do ideal descrito nas resoluções do CONAMA, pois isso pode acarretar problemas à saúde da população da região do Vale do São Francisco.

\section{REFERÊNCIAS}

ALABURDA, J; NISHIHARA, L.. Presença de compostos de nitrogênio em águas de poços. Revista Saúde Pública, v.32, n.2, p.160-165, 1998. DOI: http://doi.org/10.1590/s0034$\underline{89101998000200009}$

ANA. Agência Nacional de Águas. Panorama do enquadramento dos corpos d'água do Brasil, e, Panorama da qualidade das águas subterrâneas no Brasil. Brasília:
ANA, 2007.

ANA. Agência Nacional de Águas. Panorama da qualidade das águas superficiais no Brasil. Brasília: ANA, 2012.

ANA. Agência Nacional de Águas. Planos de recursos hídricos e enquadramento dos corpos de água. Brasília: ANA, 2013a. 
ANA. Agência Nacional de Águas. Conjuntura dos recursos hídricos no Brasil: Brasília: ANA, 2013b.

APHA. American Public Health Association. Standard Methods for examination of water and wastewater. $22 \mathrm{ed}$. Washington: APHA, 2012.

BAIRD, C.. Química Ambiental. 4 ed. Porto Alegre: Bookman, 2011.

BARRETO, R. D.. Uso e ocupação do solo às margens do Rio São Francisco no Município de Petrolina-PE: impactos ambientais no canal fluvial. Dissertação (Mestrado em Geografia) - Universidade Federal de Pernambuco, Recife, 2015.

BRAGA JÚNIOR, B. P. F.; HESPANHOL, I.; CONEJO, J. G. L.; MIERZWA, J. C.; BARROS, M. T. L.; SPENCER, M.; PORTO, M. F. A.; NUCCI, N. L. R.; JULIANO, N. M. A.; EIGER, S. . Introdução à Engenharia Ambiental. 2 ed. São Paulo: Prentice Hall, 2005.

BRASIL. Lei n. 9.433 de 8 de janeiro de 1997. Institui a Política Nacional de Recursos Hídricos, cria o Sistema Nacional de Gerenciamento de Recursos Hídricos. Brasília: DOU, 1997.

CABRAL, J. P. S.. Water microbiology. Bacterial pathogens and water. International Journal of Environmental Research and Public Health, v.7, p.3657-3703, 2010. DOI: http://doi.org/10.3390/ijerph7103657

CBHSF. Comitê da Bacia Hidrográfica do Rio São Francisco. Plano Decenal de Recursos Hídricos da Bacia Hidrográfica do Rio São Francisco: Módulo 1 (Resumo Executivo). Salvador: ANA-GEF-PNUMA-OEA, 2004.

CONAMA. Conselho Nacional do Meio Ambiente. Resolução n. 357 de 17 de março de 2005. Dispõe sobre a Classificação dos Corpos de Água e diretrizes ambientais para o seu enquadramento, bem como estabelece as condições e padrões de lançamento de efluentes, e dá outras providências. Brasília: DOU, 2005.

COSTA, E. P.; PINTO, C. C.; SOARES, A. L. C.; MELO, L. D. V.; OLIVEIRA, S. M. A. C.. Evaluation of violations in water quality standards in the monitoring network of São Francisco River basin, the third largest in Brazil Environmental Monitoring and Assessment, v.189, e.11, n.590, p.1-16, 2017. DOI: https://doi.org/10.1007/s10661-017-6266-y

DURFOR, C. N.; BECKER, E.. Public Water Supplies of the $\mathbf{1 0 0}$ largest cities in the US. 1812. Geological Survey Water Supply, 1964

FERNÍCOLA, N. G. G.; AZEVEDO, F. A.. Metemoglobinemia e nitrato nas águas. Revista de Saúde Pública, São Paulo, v.15, p.242-248, 1981.

GONÇALVES, O.. Programa de uso racional da água da USP (PURA): implementação e resultados. Revista Hydro, n.7, 2007.

INS. Instituto Nacional do Semiárido. Recursos hídricos em regiões semiáridas: Estudos e aplicações. Cruz das Almas: Universidade Federal do Recôncavo da Bahia, 2012.
JENNERJAHN, T. C.; ITTEKKOT, V.. Changes in organic matter from surface waters to continental slope sediments off the São Francisco River, eastern Brazil Marine Geology, v.161, p.129-140, 1999. DOI: https://doi.org/10.1016/S00253227(99)00045-6

KRIKA, A.; KRIKA, F.. Physico-chemical and bacteriological characterization of surface water in Djendjen River (North Eastern Algeria) Pollution, v.3, e.2, p.261-272, 2017. DOI: http://doi.org/10.7508/pj.2017.02.008

OLIVEIRA, E. C.; COSTA, K. U. D.; REIS, W. D.; SANTOS, A. A.; SILVA, W. T. P.. Diagnóstico temporal e espacial da qualidade da água superficial em uma microbacia urbana. Revista Ibero-Americana de Ciências Ambientais, v.9, n.8, p.57-69, 2018. DOI: http://doi.org/10.6008/CBPC2179$\underline{6858.2018 .008 .0006}$

OVERBY, C.. Design for sustainability and survivability. Environmental Science and Technology, v.16, n.6, p. 317A, 1982.

PAJECKI, D.. Estudo da redução de nitrato e da produção de compostos $\mathrm{N}$-nitrosos na luz esofágica, mediadas por bactérias, em pacientes portadores de megaesôfago não avançado. Tese (Doutorado em Ciências) - Universidade de São Paulo, São Paulo, 2005.

PEREIRA, A. R.; SANTOS, A. A.; SILVA, W. T. P. FROZZI, J. C.; PEIXOTO, K. L. G.. Avaliação da qualidade da água superficial na área de influência de um lixão. Ambiente \& Água - An Interdisciplinary Journal of Applied Science, v.8, n.3., p.239246, 2013. DOI: http://dx.doi.org/10.4136/ambi-agua.1160

RIZZUTTO, M. A.; ADDED, N.; TABACNIKS, M. H.; ESPINOZAQUIÑONES, F. R.; PALACIO, S. M.; GALANTE, R. M.; ROSSI, N.; ZENATTI, D. C.; ROSSI, F. L.; WELTER, R. A.; MÓDENES, A. N.. Trace element concentrations from São Francisco River - PR analyzed with PIXE technique. Journal of Radioanalytical and Nuclear Chemistry, v.269, n.3, p.727-731, 2006. DOI: http://doi.org/10.1007/s10967-006-0422-0

SILVA, B. B.; ROCHA, L. G.; SILVEIRA, L. P. O.; CARVALHO, A. V.; GUIMARÃES, A. P. M.. Análise de qualidade da água do Ribeirão Tranqueira. Revista Ibero-Americana de Ciências Ambientais, v.9, n.8, p.11-25, 2018. DOI: http://doi.org/10.6008/CBPC2179-6858.2018.008.0002

SILVA, M. A.; ARAÚJO, R. R.. Análise temporal da qualidade da água no córrego Limoeiro e no rio Pirapozinho no estado de São Paulo - Brasil. Revista Formação, v.1, n.24, p.182203, 2017.

SILVA, P. S.; CAGNI, G. S.; LIZAMA, M. A. P.; GONÇALVES, J. E.. Avaliação da qualidade de água: concepção hidrossanitária da Bacia do Rio do Campo, Paraná, Brasil. Revista Ibero-Americana de Ciências Ambientais, v.9, n.8, p.26-38, 2018. DOI: http://doi.org/10.6008/CBPC2179$\underline{6858.2018 .008 .0003}$

ZHANG, Z.; WANG, J. J.; ALI, A.; DELAUNE, R. D.. Heavy metal distribution and water quality characterization of water bodies in Louisiana's Lake Pontchartrain Basin, USA. Environmental Monitoring and Assessment, v.188, e.11, n.628, p.1-14, 2016. DOI: http://doi.org/10.1007/s10661016-5639-y

A CBPC - Companhia Brasileira de Produção Científica (CNPJ: 11.221.422/0001-03) detém os direitos materiais desta publicação. Os direitos referem-se à publicação do trabalho em qualquer parte do mundo, incluindo os direitos às renovações, expansões e disseminações da contribuição, bem como outros direitos subsidiários. Todos os trabalhos publicados eletronicamente poderão posteriormente ser publicados em coletâneas impressas sob coordenação da Sustenere Publishing da Companhia Brasileira de Produção Científica e seus parceiros autorizados. Os (as) autores (as) preservam os direitos autorais, mas não têm permissão para a publicação da contribuição em outro meio, impresso ou digital, em português ou em tradução. 